\title{
Effects of Socially Responsible Behaviors in a Supply Chain under Carbon Cap-and-Trade Regulation
}

\author{
Guobao Zhang, ${ }^{1}$ Leizhou Zhao, ${ }^{2}$ Qing Zhang $\mathbb{D}^{3},{ }^{3}$ and Zhichao Zhang $\mathbb{D}^{1,3}$ \\ ${ }^{1}$ Department of Management, Anhui Science and Technology University, Bengbu 233100, China \\ ${ }^{2}$ Department of Material Management, Shanghai Aerospace Equipments Manufacturer Co., Ltd., Shanghai 201100, China \\ ${ }^{3}$ College of Economics and Management, Nanjing University of Aeronautics and Astronautics, Nanjing 211106, China
}

Correspondence should be addressed to Qing Zhang; karlnuaa@nuaa.edu.cn

Received 12 May 2021; Revised 11 August 2021; Accepted 20 October 2021; Published 2 November 2021

Academic Editor: Giulio E. Cantarella

Copyright (c) 2021 Guobao Zhang et al. This is an open access article distributed under the Creative Commons Attribution License, which permits unrestricted use, distribution, and reproduction in any medium, provided the original work is properly cited.

Recently, many firms in various industries implement corporate social responsibility (CSR) in different ways. Based on considering a CSR-concerned retailer and an altruistic fairness concern manufacturer, this paper investigates pricing decisions as well as carbon emission policies in a socially responsible supply chain. In this paper, two different modes (the centralized model and decentralized model) are, respectively, conducted and investigated for equilibria. Analytical results reveal that socially responsible retailer (manufacturer) cares more about CSR (altruistic fairness) concern and will increase his counterpart's pure profit as well as the pure channel profit, ending up with decreasing his own pure profit. The cooperative agents in decentralized scenario can coordinate the channel and achieve the maximum pure channel profit as much as that in a pure profit-maximizing centralized model. Moreover, this paper proposes a novel two-stage carbon cap-and-trade policy for the government and examines how it is affected by the CSR concern level and the altruistic fairness in such a socially responsible supply chain.

\section{Introduction}

Environmental polluting emerging as a worldwide consensus has caught attention from the practitioners and academia. When carrying out business, enterprises increasingly actively or passively manage the negative impacts of their activities on society, such as designing a sustainable product [1], applying new technology with less emission [2], recycling the end-of-use products [3] to pursue economic benefits, following the governmental regulation, and catering for consumers' awareness. In 2009, a total of 186 firms with assets valuated at 13 trillion US dollars agreed upon and signed a statement to propose plans to mitigate global warming by reducing greenhouse gas emissions $[4,5]$. In the past decades, a rich group of regions and countries have issued a series of policies to deal with climate problems and diminish greenhouse gas emissions. By the year of 2009, a total of 183 countries signed the Kyoto protocol, which went into effect in 2005, to impose global emission reduction [6]. European Union (EU) firstly launched an emissions trading scheme in 2005, which has become the largest carbon trading market in the world [7]. In China, the government promised to peak carbon emission by 2030 and reach carbon neutralization by 2060 in 2020 and is planning to formulate relevant policies. Emission trading systems have currently been adopted by these countries, such as Australia, New Zealand, United States, Japan, and China. Carbon cap-and-trade mechanism, deemed to be one of the most effective attempts among above measures, has been largely implemented in many nations around the world. For example, it has been reported that the total amount of carbon emission trading has exceeded 50 billion dollars in 2010 [8]. Therefore, how to curb carbon emissions becomes a crucial issue for a firm partly due to attain economic profitability and partly due to concern about environmental effects [9].

Corporate social responsibility (CSR), focusing on the fact that firms should account for their shareholders' financial responsibility as well as social responsibility to their numerous stakeholders, has been caught notable attention in 
both the industry and the academia in recent years $[5,10,11]$. It is said that $81 \%$ companies state their CSR declarations on their websites in 2010 by Price Waterhouse Coopers [12]. KPMG reports that approximately $80 \%$ of the world's largest 250 firms reveal CSR reports [13]. The largest apparel retailer GAP promises to improve its working conditions in as many as 3000 factories worldwide [14]. Dell takes its social responsibility mainly by investing more on sustainable technology, designing a low-energy-efficiencylevel product, and recycling electronic waste to reduce environmental pollution of their products (https://www.dell. com/learn/cn/zh/cncorp $1 / \mathrm{cr}, 2018$ ). It is reported that, during the epidemic, more than 4000 Chinese enterprises donated 35.14 billion yuan partly to combat COVID-19 and partly to take the corporate social responsibility in 2020 (https://finance.sina.com.cn/esg/sr/2020-11-19/doc-

iiznezxs2694796.shtml). Following the notion in $[15,16]$, we develop a supply chain with CSR-concerned member(s), defined as a socially responsible supply chain. In this research, we adopt consumer surplus as a proxy of CSR concerns by following existing literature [17-19].

Firms now pay considerable attention to the distributional fairness of the profit in a supply chain, and such fairness concerns are crucial for developing and maintaining cooperative relations. Moreover, decision-makers with fairness concerns focus on the income gap between themselves and the other participants. Specifically, the fairness of inequity holds for the individual when his allocated profit is less than his counterparts; otherwise, the fairness of altruism is exhibited when his profit is more than his counterparts. In a practical perspective, Gree, the largest air-conditioning manufacturer in China, had distributional inequity conflict between Gree's returns and Gome, China's largest household appliance retailer in 2003. Gome wanted to sell Gree's products by making small profits but quick turnover, which is ultimately rejected by Gree. Under several rounds of fruitless negotiations, consequently, Gome stopped to sell Gree's products in its distributional channel in 2004 [20]. This leads to Gree's sales growth decline with an appropriately five percent in the next two years. It is noteworthy that Gree and Gome signed a strategic agreement that they will deeply cooperate on servicing consumers, widening distribution channels, and strengthening brand value in 2017. They expected to sell Gree's products with value at 100 million in Gome and succeeded. This clearly shows a socially responsible leader; it should account for its follower's profit and thus exhibit altruistic fairness concern.

To the best of our knowledge, it remains largely unexplored to incorporate carbon cap-and-trade regulation into a socially responsible supply chain with members taking CSR in different ways. This paper makes a first attempt to investigate pricing decisions for socially responsible member(s) with different CSR behaviors in the presence of capand-trade regulation. In more detail, this paper embeds CSR concerns level and altruistic fairness concern to a socially responsible supply chain and aims to examine their significant impacts on the optimal decisions and profitability for the supply chain and its members. Due to posing up priority in market, this paper considers the manufacturer as a Stackelberg leader who exhibits altruistic distributional fairness and the retailer as the follower with concerning on CSR. To be specific, the research questions of this paper are formulated as follows:

(1) How to determine the optimal pricing decisions for the socially responsible member in two different models (i.e., integrated model and decentralized model) in the contexts of carbon cap-and-trade regulation?

(2) How CSR concern level and the altruistic fairness concerns affect the performances of the individuals and the channel? What are the best CSR concern level and the distributional fairness for the supply chain?

(3) Can the government formulate an appropriate carbon regulation policy, i.e., carbon trade price and carbon cap, in this socially responsible supply chain? What are the impacts of CSR concern level and the altruistic fairness on the cap-and-trade policy?

The contribution of this paper is devoted to the existing literature from the following streams. Firstly, the current work investigates how the socially responsible behavior (CSR concerned by the retailer and the altruistic fairness concern by the manufacturer) affects the operational decisions and supply chain performance under the carbon capand-trade regulation. This paper finds that socially responsible retailer (manufacturer) cares more about CSR (the retailer's distributional profit) and will increase his counterpart's pure profit as well as the pure channel profit, ending up with decreasing his own pure profit. In addition, we interestingly find that the decentralized channel can achieve the maximum pure profit as much as that in a pure profitmaximizing centralized channel by incorporating an appropriate CSR concern level. This result shows that taking CSR will generate economic benefits for the supply chain under certain conditions. Secondly, this paper explicitly explores the effects of carbon cap-and-trade policy on this socially responsible supply chain. The fundamental differences between this paper and the existing literature lie in that this paper proposes a novel two-stage carbon cap-and-trade policy in such a socially responsible supply chain and proves its feasibility in the carbon trading market. By applying this two-stage carbon cap-and-trade policy, it is found that the differences of supply chain performances between the centralized and decentralized models are exhibited in carbon trading market rather than product selling market, which makes the government regulate and control product selling market possible by determining appropriate carbon capand-trade policy.

The remainder of this paper is organized as follows. The relevant literature closely related to this study is exhibited in Section 2. Section 3 details the notations and the base models in both centralized and decentralized models, with the equilibrium pricing decisions and the performances of the supply chain and its members in two different models. Section 4 mainly investigates the effects of the key parameters on the equilibrium and performance of the supply 
chain and then compares the supply chain performance in the both centralized and decentralized models. This paper proposes a novel two-stage carbon cap-and-trade policy for the government and proves its feasibility in Section 5 . The numerical analysis is provided in Section 6. Section 7 concludes the paper with the main implications and gives further research.

\section{Literature Review}

The related researches regarding this paper can be categorized into three streams: carbon cap-and-trade regulation, corporate social responsibility, and distributional fairness concern.

2.1. Carbon Cap-and-Trade Regulation. In the existing literature, many researchers focus on different carbon emission policies, such as carbon cap [21], carbon tax [22], and carbon cap-and-trade [23]. Constructing a socially responsible supply chain under carbon cap-and-trade mechanism, the aim of this paper is to analyze the pricing decisions and carbon policies in the context of carbon regulation. As a result, the literature referring to this stream can be classified into two dimensions: operational decisions and carbon policies in cap-and-trade regulation.

As for operational decisions, Hua et al. [24] discuss the optimal order quantity, carbon trade, carbon price, and carbon cap in inventory management under the cap-andtrade mechanism. Chen et al. [20] explore the best order quantity and strategies to reduce emissions under cap-andtrade regulation based on economic order quantity (EOQ) model. Du et al. [25] focus on the impact of carbon cap-andtrade mechanism in an emission-dependent supply chain with one emission permit supplier and one emission-dependent firm. Xu et al. [26] study the joint pricing and production decisions of multiple products in different carbon policies, i.e., a cap-and-trade mechanism and carbon tax regulation. Du et al. [9] introduce low-carbon effort of an environmentally concern firm into a game-theoretical supply chain to investigate the decentralized operational managements of the manufacturer and retailer. Xu et al. [27] examine the selling price, sustainability investment, and coordination mechanisms of a sustainable supply chain considering a cap-and-trade system.

In terms of carbon policies in supply chain, Letmathe and Balakrishnan [28] develop two different mathematical models to optimize product strategy and production quantities and maximize their profit of firms under distinct environmental regulations. Zhang et al. [8] explore the best production policies of the manufacturer in the context of stochastic demand in the carbon cap-and-trade mechanism. Song and Leng [29] address a classical single-period newsvendor problem under different carbon emissions policies including the mandatory carbon emissions cap, the carbon emissions tax, and the cap-and-trade regulation. Du et al. [30] concentrate on a emission-dependent supply chain system in the contexts of carbon cap-and-trade system and investigate how emission cap impacts decision-makings within a concerned emission-dependent supply chain as well as distribution fairness in social welfare. Zhou et al. [31] investigate the impacts of a low-carbon policy instrument by a case of carbon tax on transportation in China. Micheli and Mantella [32] propose four different carbon policies, namely, the carbon tax, the cap, the cap-and-trade, and the cap-andoffset by modelling the problem with the consideration of the uncertainty in customer demand, a comprehensive emissions model, and a heterogeneous fleet of vehicles simultaneously. Xia et al. [23] study carbon emission reduction and promotion policies in the presence of social preferences and consumers' low-carbon awareness under carbon cap-and-trade regulation.

The aforementioned studies focus on carbon cap-andtrade system mainly from a traditional supply chain. Few of them pay much attention to pricing and operation under a carbon cap-and-trade regime for a socially responsible supply chain. This paper investigates the scenario in which the carbon cap-and-trade mechanism is introduced to a socially responsible supply chain and explores the optimal carbon policy for the government. For balancing the firms' profits and the social benefits, a novel two-stage carbon capand-trade policy is proposed for the government and proved feasible in industrial practice.

2.2. Corporate Social Responsibility. Corporate social responsibility, not only accounting for corporate immediate profit, but also accounting for the sustainable development of the firm, has caught notable attention in recent researches. Some literatures have reported quantitative and empirical studies of applications and impacts of CSR. Carter and Jennings [33] explore CSR investments in decisions of a supply chain by case studies and point out that a supplier with CSR can draw notable attention from the society. Miao et al. [34] use Chinese firms as a sample to investigate the antecedents of logistics social responsibility. Carter et al. [35] find that the implementation of CSR is conducive to strengthen the performance of the suppliers. Wang et al. [36] explore the relationships among corporate social responsibility, brand equity, and firm performance by using quantile regression and structural equation with case study in Taiwanese high-tech companies over the period 2010-2013. Albuquerque et al. [37] investigate the corporate social responsibility and firm risk within theory and empirical evidence.

In terms of socially responsible supply chain, two streams exploring how CSR strategy affects the operations and performance are commonly investigated in a supply chain. On the one hand, many studies regard CSR as a continuous investment for the socially responsible firm and show that this CSR input has a critical impact on the operation and performance in a supply chain. For example, Hsueh and Chang [38] conduct a three-stage supply chain consisting of devised manufacturers, distributors, and retailers and then evaluate how to coordinate the profit distribution between manufacturers on CSR. A similar research also found that manufacturer's CSR efforts or retailer's CSR efforts exert an important effect on the supply chain's profit 
and its coordination $[11,39,40]$. On the other hand, the other researching line regarding measuring CSR performance is by applying consumer surplus as a proxy of CSR concerns for a socially responsible individual. For example, this CSR concern by characterizing consumer surplus has been widely investigated in a stylized supply chain [38,41], three-stage supply chain [42], and a closed loop supply chain $[16,18]$.

Extant literature concentrates on CSR placed by the retailer or the manufacturer in a traditional supply chain. This paper develops a two-tier socially responsible supply chain, with two socially responsible members acting differently; i.e., the socially responsible retailer places a CSR concern level on consumer surplus, while the socially responsible manufacturer exhibits an altruistic fairness to its retailer. This paper aims to seek the best CSR weights for maximizing both the pure and socially responsible profits.

\subsection{Distributional Fairness Concern. The third stream of} literature with regard to this paper is researching on the distributional fairness concerns in a supply chain. Cui et al. [43] incorporate the concept of fairness concerns into a supply chain consisting of a manufacturer and a retailer, in which a retailer or both members are fairness-concerned. It shows how fairness concerns affect the profit distribution between the manufacturer and the retailer and how to coordinate the supply chain by applying the two-part tariffs and quantity discounts contracts. Du et al. [44] explore newsvendor problem in a supply chain, where both the supplier and the retailer possess Nash bargaining fairness concerns. It is uncovered that the channel efficiency will decrease in the presence of such a behavioral preference. Nie and $\mathrm{Du}$ [45] study quantity discount contracts in a supply chain that consists of one supplier and two peer retailers, in which the retailers exhibit peer-induced fairness concern. Their study demonstrates that the quantity discount contracts cannot coordinate this supply chain under behavioral concerns and therefore propose a coordination mechanism combining quantity discount contracts with fixed fees. $\mathrm{Du}$ et al. [46] research a distribution channel that consists of a supplier with two retailers located in independent markets, in which the retailer cares about his peer-induced fairness. Wang et al. [47] investigate operational decisions and coordination of an e-commerce supply chain, consisting of a manufacturer and an e-commerce platform, in the context of manufacturer's distributional fairness concerns. Their research shows that the manufacturer distributional fairness concerns reduce system efficiency.

All the above papers highlight the fairness concerns that play a significant role in the supply chain performances and coordinating a supply chain. However, most of them analyze how the self-interest distributional fairness affects the supply chain members' allocated profits from the perspective of the Stackelberg follower. As a socially responsible leader, he should account not only for his own profit, but also for the allocated profit of his follower. Specifically, the Stackelberg leader feels altruistic when he obtains more allocated profit than his follower. This is why we incorporate the altruistic fairness that the Stackelberg leader exhibits to the socially responsible supply chain.

In summary, we summarize the key differences between this paper and the existing studies in Table 1.

\section{Notations and Model Formulation}

3.1. Notations. To facilitate the development of the model, the notations are introduced in Table 2.

In this paper, we develop a single-period and twoechelon socially responsible supply chain consisting of one manufacturer and one retailer, in which the retailer is CSRconcerned, and the manufacturer exhibits altruistic fairness. The manufacturer produces the product and charges a unit wholesale price $w$ to the retailer who then sells the product to the end consumers at a retail price $p$. This paper adopts linear demand function by following the related literature in supply chain [50] as

$$
D(p)=a-\beta p,
$$

where $a>0$ denotes the market potential, and $\beta>0$ stands for the price sensitivity factor of demand. This demand function clearly implies a retail price cap as $0<p<(\alpha / \beta)$.

To focus on a socially responsible behavior, this paper gauges CSR performance for a socially responsible individual by adopting consumer surplus as a proxy of CSR concerns. Consumer surplus measures the welfare that consumers obtain by purchasing goods or services. It is gauged as the difference between what the consumers are willing to pay and what they actually pay for the product or the services $[15,18]$. Given the demand function in equation (1), we can thus compute the consumer surplus as follows:

$$
\int_{P_{\min }}^{P_{\max }} D(p) \mathrm{d} p=\int_{p}^{a / \beta}(a-\beta p) \mathrm{d} p=\frac{(a-\beta p)^{2}}{2 \beta} .
$$

Furthermore, as a socially responsible individual in decentralized case and a central planner in the centralized case, they incorporate a fraction $\theta \in[0,1]$ of consumer surplus into their objective function when making the operational decisions. Therefore, the socially responsible concern component is achieved as

$$
\operatorname{CSR}=\frac{\theta(a-\beta p)^{2}}{2 \beta},
$$

where $\theta=0$ implies that the supply chain member is a pure profit maximizer, a higher $\theta$ indicates a more socially responsible individual, and $\theta=1$ signifies that the supply chain member is a perfect socially responsible profit maximizer.

Under the carbon cap-and-trade regulation, firms are first assigned a given quota carbon cap $K$ to emit in a single period. Manufacturing one product will cost a unit carbon emission $e$. The additional (surplus) carbon emission quotas are allowed to purchase (sell) in the carbon trading market with a unit carbon trade price $\lambda$ determined by the government. If the total carbon emission from production side, i.e., $e D$, is larger than the given cap $K$, an additional expense for the manufacturer to purchase the insufficient carbon 
TABLE 1: Our paper vs. the other key literature.

\begin{tabular}{lcccccc}
\hline Authors & CC & DF & CAT & CP & Focus \\
\hline Albuquerque et al. [37] & $\sqrt{ }$ & $\times$ & $\times$ & $\times$ & CSR, Firm risk, empirical analysis \\
Bian et al. [17] & $\sqrt{ }$ & $\times$ & $\times$ & $\times$ & CSR, managerial incentive design, Bertrand competition, Cournot competition \\
Panda [48] & $\sqrt{ }$ & $\times$ & $\times$ & $\times$ & CSR, channel coordination, revenue sharing contract \\
Son et al. [49] & $\sqrt{ }$ & $\sqrt{ }$ & $\times$ & $\times$ & Fair treatment of suppliers, CSR, social exchange theory \\
Cui et al. [43] & $\times$ & $\sqrt{ }$ & $\times$ & $\times$ & Fairness, channel coordination, behavioral economics \\
Du et al. [25] & $\times$ & $\sqrt{ }$ & $\times$ & $\times$ & Peer-regarding fairness, sympathy, behavioral operations management \\
Du et al. [46] & $\times$ & $\times$ & $\sqrt{ }$ & $\sqrt{ }$ & Carbon cap-and-trade policy, emission-dependent \\
Xia et al. [23] & $\times$ & $\times$ & $\times$ & $\sqrt{ }$ & Cap-and-trade, carbon emission reduction, channel coordination \\
Our model & $\sqrt{ }$ & $\sqrt{ }$ & $\sqrt{ }$ & $\sqrt{ }$ & CSR, altruistic fairness, cap-and-trade, policy making \\
\hline
\end{tabular}

Notes. CC denotes CSR concern, DF represents distributional fairness, CAT corresponds to cap-and-trade, and CP means carbon policy making for the government.

TABLE 2: List of notations.

\begin{tabular}{lc}
\hline Parameters & Definitions \\
\hline$c$ & The unit cost of producing a new product \\
$\beta$ & The price sensitivity factor of demand \\
$a$ & The market potential \\
$e$ & The unit carbon emission for manufacturing a new product \\
$\theta$ & The fraction of consumer surplus \\
$d$ & The unit negative impact for manufacturing and selling a new product on environment \\
$\delta$ & The manufacturer's altruistic fairness concern \\
$D$ & The demand \\
CSR & Socially responsible concern component \\
SW & Social welfare \\
\hline & Decision variables \\
$p$ & The retail price of the product \\
$w$ & The wholesale price of the product \\
$K$ & The carbon cap \\
$\lambda$ & The unit carbon trading price \\
\hline & Superscript/subscripts \\
$*$ & The equilibrium strategies in different models \\
$\pi_{i}^{j}$ & manufacturer, and retailer, respectively, and the superscript $D$ and $C$ stand for models $D$ and $C$, respectively. \\
$V_{i}^{j}$ & The socially responsible profit of participant $i$ in model $j, i \in\{S C, M, R\}, j \in\{D, C\}$.
\end{tabular}

emission quotas as $\lambda(e D-K)$ is necessary. Otherwise, the manufacturer obtains a revenue by selling surplus emission quotas as $\lambda(K-e D)$. Accordingly, the pure profits of the manufacturer and the retailer are achieved as follows:

$$
\begin{aligned}
\pi_{M}^{D} & =(w-c) D-\lambda(e D-K), \\
\pi_{R}^{D} & =(p-w) D .
\end{aligned}
$$

For equation (4), the first term gauges the gross profit by selling the product to the end consumers, and the second term measures the expense (revenue) of purchasing (selling) the additional (surplus) carbon emission quotas. Observing that the leader always grabs more revenue shares than his follower in a Stackelberg game [16], the socially responsible manufacturer exhibits the altruistic distributional fairness concerns with regard to its downstream retailer. Specifically, the socially responsible manufacturer poses an altruistic preference to maintain the long-term profit of the whole supply chain. A higher altruistic preference represents that the manufacturer will perceive a higher negative utility about the profit gap between the manufacturer and the retailer. Following the model [45], the manufacturer's socially responsible profit function thus consists of his pure profit and the utility about profit gap of the retailer, which is shown as follows:

$$
V_{M}^{D}=\pi_{M}^{D}-\delta\left(\pi_{M}^{D}-\pi_{R}^{D}\right)
$$

where $\delta \geq 0$ captures the manufacturer's altruistic distributional fairness concern, and the lager $\delta$ represents the manufacturer concerning more about the retailer's distributional profits.

This paper shall next investigate the decentralized case, in which the retailer is CSR-concerned, and the manufacturer exhibits an altruistic distributional fairness, referred to as Model $D$. As a benchmark, we then develop a centralized supply chain, where a central planner makes operational decision and is CSR-concerned, referred to as Model C. For notational convenience, this paper defines the following 
notations as $M_{1}=2-\theta-\delta(3-2 \theta), \quad M_{2}=2-\theta-\delta$ $(4-3 \theta), M_{3}=3-2 \theta-\delta(5-4 \theta), M_{4}=6-3 \theta-\delta(6-4 \theta)$, $M_{5}=5-2 \theta-\delta(7-4 \theta), T=a-\beta c-\beta \lambda e$ and $G=a-\beta c-$ $\beta d$ with assumptions that $T>0$ and $G>0$. In a decentralized case, the manufacturer is supposed to be the Stackelberg leader, while the retailer is the Stackelberg follower.

3.2. The Decentralized Scenario (Model D). In decentralized scenario, this paper develops a socially responsible supply chain consisting of one manufacturer and one retailer under cap-and-trade regulation, where the retailer is CSR-concerned, and the manufacturer exhibits the altruistic fairness. The Stackelberg leader and manufacturer make the first move to produce the products and then wholesale them to the retailer at a wholesale price $w$. The Stackelberg follower and retailer then determine a price $p$ and directly retail the products to the end market. In this scenario, the retailer maximizes its socially responsible profit consisting of the pure profit and a fraction of consumer surplus, shown as follows:

$$
V_{R}^{D}=\pi_{R}^{D}+\operatorname{CSR}_{R}^{D}=(p-w) D+\frac{\theta D^{2}}{2 \beta} .
$$

The manufacturer's optimization is to maximize the socially responsible profit, which is composed of the pure profit and the negative utility about profit gap beyond the retailer. The socially responsible profits of the manufacturer are thus obtained as follows:

$$
V_{M}^{D}=\pi_{M}^{D}-\delta\left(\pi_{M}^{D}-\pi_{R}^{D}\right)
$$

where $\delta \geq 0$ implies the manufacturer's altruistic fairness concern. In particular, $\delta=0$ corresponds to a special case when the manufacturer is distribution-fairness-neutral, and a higher $\delta$ indicates that the manufacturer pays more attention to the retailer's distributional profits. Accordingly, the socially responsible channel profit is the sum of the manufacturer's and retailer's socially responsible profits as $V_{\mathrm{SC}}^{D}=V_{M}^{D}+V_{R}^{D}$. Equilibrium pricing decisions and the performance of the supply chain in Model $D$ are derived by applying backward induction, which are, respectively, shown in Propositions 1 and 2.

Proposition 1. In Model D, one can derive the following equilibrium pricing decisions:

$$
\begin{aligned}
& w^{D *}=\frac{a}{\beta}-\frac{T(1-\delta)(2-\theta)}{2 \beta(2-\theta-\delta(3-2 \theta))}, \\
& p^{D *}=\frac{a}{\beta}-\frac{T(1-\delta)}{2 \beta(2-\theta-\delta(3-2 \theta))} .
\end{aligned}
$$

Proof. See Appendix A. Without loss of generality, the two constraints $p^{D *}<(a / \beta)$ and $w^{D *}>c+\lambda e$ should be satisfied in Model $D$. Therefore, we can address that $0<\delta<(1 / 2)$. Substituting $p^{D *}$ and $w^{D *}$ into the corresponding performances of the individuals and the channel, Proposition 2 is thus formulated.
Proposition 2. In Model D, the performance of the individual and the channel is confirmed as follows:

$$
\begin{aligned}
\pi_{R}^{D *} & =\frac{(1-\delta)^{2}(1-\theta) T^{2}}{4 \beta M_{1}^{2}}, \\
V_{R}^{D *} & =\frac{T^{2}(1-\delta)^{2}(2-\theta)}{8 \beta M_{1}^{2}}, \\
\pi_{M}^{D *} & =\frac{T^{2}(1-\delta) M_{2}}{4 \beta M_{1}^{2}}+\lambda K, \\
V_{M}^{D *} & =\frac{T^{2}(1-\delta)^{2}}{4 \beta M_{1}}+(1-\delta) \lambda K, \\
\pi_{\mathrm{SC}}^{D *} & =\frac{T^{2}(1-\delta) M_{3}}{4 \beta M_{1}^{2}}+\lambda K, \\
V_{\mathrm{SC}}^{D *} & =\frac{T^{2}(1-\delta)^{2} M_{4}}{8 \beta M_{1}^{2}}+(1-\delta) \lambda K .
\end{aligned}
$$

Proof. See Appendix A.

3.3. The Centralized Scenario (Model C). In centralized scenario, a central decision-maker represents the interests of the manufacturer and the retailer and retails the products directly to the end consumers. In this scenario, the central decision-maker determines the retail price under cap-andtrade regulation. Similarly, the objective functions of the pure and socially responsible channel profit are thus given by

$$
\begin{aligned}
\pi_{\mathrm{SC}}^{C} & =(p-c) D-\lambda(e D-K), \\
V_{\mathrm{SC}}^{C} & =\pi_{\mathrm{SC}}^{C}+\mathrm{CSR}_{\mathrm{SC}}^{C}=(p-c) D-\lambda(e D-K)+\frac{\theta D^{2}}{2 \beta} .
\end{aligned}
$$

The equilibrium pricing decision and the performance in centralized scenario are collected in Proposition 3.

Proposition 3. In Model $C$, the equilibrium pricing decision and the channel profit are confirmed as follows:

$$
\begin{aligned}
& p^{C *}=\frac{a}{\beta}-\frac{T}{\beta(2-\theta)}, \\
& \pi_{\mathrm{SC}}^{C *}=\frac{T^{2}(1-\theta)}{\beta(2-\theta)^{2}}+\lambda K, \\
& V_{\mathrm{SC}}^{C *}=\frac{T^{2}}{2 \beta(2-\theta)}+\lambda K .
\end{aligned}
$$

Proof. See Appendix B. 


\section{Analysis of the Socially Responsible Behavior}

This section, respectively, investigates the impacts of the two different socially responsible behaviors, i.e., the CSR concern placed by the socially responsible retailer and the distributional altruistic fairness concerned by the socially responsible manufacturer, on the supply chain. To be specific, we first carry out the sensitivity analysis regarding two important parameters, i.e., the retailer's CSR concern level $\theta$ and the manufacturer's altruistic fairness $\delta$ on the equilibrium decisions and the supply chain performance. The comparisons of the performances with different CSR concern level in centralized and decentralized models are then obtained.

\subsection{The Effects of CSR Concern Level}

Corollary 1. In the decentralized and centralized models, one can derive the effects of CSR concern level on the equilibrium pricing decisions and supply chain performance as follows:
(a) $\left(\partial p^{C *} / \partial \theta\right)<0,\left(\partial \pi_{S C}^{C *} / \partial \theta\right)<0$, and $\left(\partial V_{S C}^{C *} / \partial \theta\right)>0$
(b) $\left(\partial p^{D *} / \partial \theta\right)<\left(\partial w^{D *} / \partial \theta\right)<0$
(c) $\left(\partial \pi_{R}^{D^{*}} / \partial \theta\right)<0,\left(\partial \pi_{M}^{D^{*}} / \partial \theta\right)>0$, and $\left(\partial \pi_{S C}^{D^{*}} / \partial \theta\right)>0$
(d) If $0<\delta<((2-\theta) /(5-2 \theta))$ then $\left(\partial V_{R}^{D^{*}} / \partial \theta\right)>0$; if $0<((2-\theta) /(5-2 \theta))<\delta$ then $\left(\partial V_{R}^{D^{*}} / \partial \theta\right)<0$
(e) $\left(\partial V_{M}^{D^{*}} / \partial \theta\right)>0$ and $\left(\partial V_{S C}^{D^{*}} / \partial \theta\right)>0$

Proof. See Appendix C. Corollary 1(a) shows how CSR concern level impacts the optimal pricing decisions and the channel performance in centralized case. The central planner understandably charges a relatively low retail price to enhance the consumer surplus when it is more CSR-concerned $\left(\left(\partial p^{C *} / \partial \theta\right)<0\right)$. We can infer that the resulting demand thus increases with a heavier CSR concern level $\left(\left(\partial D^{C *} / \partial \theta\right)>0\right)$ in Model $C$, as the resulting demand is inversely proportional to the retail price. This signifies that the increased revenue owing to a larger resulting demand is insufficient to counterbalance the decreased profit due to a lower retail price as $\left(\partial \pi_{\mathrm{SC}}^{C *} / \partial \theta\right)<0$. Given that $\operatorname{CSR}^{C}=\left(\theta D^{2} / 2 \beta\right)$, it is clear that the central planner enjoys a higher CSR with placing a heavier CSR concern level. Note that $\left(\partial V_{\mathrm{SC}}^{C *} / \partial \theta\right)>0$, and the channel will achieve more socially responsible profits when placing a larger weight on CSR. In summary, when the central planner is more CSR-concerned, the supply chain achieves more CSR, ending up with giving up some pure profits, and the increased CSR is more to compensate the loss of the pure profit, thereby enhancing the socially responsible channel profit.

Corollary 1(b) discloses how the CSR concern level affects the pricing decisions in decentralized model. Parallel to Corollary 1(a), the Stackelberg follower and socially responsible retailer first charge a lower retail price to stimulate consumer surplus, and then the Stackelberg leader and manufacturer subsequently pull down its wholesale price. In addition, an increase in CSR concern level decreases the retail price faster than the wholesale price. The resulting demand and the CSR component in decentralized case change in a similar pattern with that in the centralized case. Similarly, the supply chain will charge a lower retail price to boost consumer surplus when it is more CSR-concerned, thereby enhancing the resulting demand and the CSR component in the decentralized case.

Regarding the pure profits of the individuals and the channel, Corollary 1(c) clearly implies that a heavier weight on CSR will decrease the retailer's pure profit while increasing the manufacturer's pure profit in Model D. This occurs because the wholesale price decreases at a smaller pace than retail price, signifying that the profit gain owing to the larger resulting demand is more (less) to compensate the profit loss due to a lower wholesale (retail) price for the manufacturer (retailer). Additionally, the decreased pure profit for the retailer is less than the increased pure profit for the manufacturer. As a result, an increase in the CSR concern level increases the pure channel profit as $\left(\partial \pi_{\mathrm{SC}}^{D^{*}} / \partial \theta\right)>0$. To sum up, a higher CSR concern level decreases the pure channel profit in centralized case, yet it increases the pure channel profit in the decentralized case. When the socially responsible retailer places more weights on CSR, it decreases the retailer's pure profit but increases the manufacturer's pure profit in decentralized case. Observe that $\left(\partial \pi_{M}^{D^{*}} / \partial \theta\right)-\left(\partial \pi_{R}^{D^{*}} / \partial \theta\right)>0$, and it suggests that the pure profit gap between the manufacturer and retailer is enlarged when the retailer is more CSR-concerned.

In Corollary 1(d), whether a higher CSR concern level increases or decreases the socially responsible profit for the retailer relies largely on the manufacturer's altruistic fairness. To be specific, when the manufacturer cares more about the retailer's distributional profit as $\delta>((2-\theta) /(5-2 \theta))$, the retailer obtains fewer socially responsible profit when placing a heavier weight on CSR. Otherwise, the retailer will achieve more socially responsible profits with a higher CSR concern level when the manufacturer concentrates less about the altruism preference as $0<\delta<((2-\theta) /(5-2 \theta))$. Note that $((2-\theta) /(5-2 \theta))$ decreases in $\theta$; thus, we can obtain $(1 / 3)<((2-\theta) /(5-2 \theta))<(2 / 5)$. In more detail, an increase in CSR concern level $\theta$ increases the retailer's socially responsible profit when $0<\delta<(1 / 3)$, decreases the retailer's socially responsible profit when $(2 / 5)<\delta<(1 / 2)$, and exerts an ambiguous effect on the retailer's socially responsible profit when $(1 / 3)<\delta<(2 / 5)$.

Corollary 1(e) indicates that both the manufacturer and the channel achieve more socially responsible profits when the retailer is more CSR-concerned. This naturally happens on one hand, when the manufacturer's altruistic fairness concern is not excessive as $0<\delta<((2-\theta) /(5-2 \theta))$, and both the manufacturer and the retailer enjoy more socially responsible profits. On the other hand, when the manufacturer's altruistic fairness concern is excessive as $\delta>((2-\theta) /(5-2 \theta))$, the increased socially responsible profit for the manufacturer is much more to compensate the socially responsible profit loss for the retailer, leading to more socially responsible channel profit with a heavier CSR concern level as $\left(\partial V_{\mathrm{SC}}^{D^{*}} / \partial \theta\right)>0$. 


\subsection{The Effects of the Altruistic Fairness}

Corollary 2. In the decentralized model, one can derive the impacts of the manufacturer's altruistic distributional fairness on the equilibrium pricing decisions and performances of the supply chain and its members as follows:

(a) $\left(\partial w^{D *} / \partial \delta\right)<\left(\partial p^{D *} / \partial \delta\right)<0$

(b) $\left(\partial \pi_{M}^{D^{*}} / \partial \delta\right)<0, \quad\left(\partial \pi_{R}^{D^{*}} / \partial \delta\right)>0, \quad\left(\partial \pi_{S C}^{D^{*}} / \partial \delta\right)>0$, and $\left(\partial V_{R}^{D^{*}} / \partial \delta\right)>0$

(c) (i) If $\theta \in((1 / 2), 1)$, then $\left(\partial V_{M}^{D^{*}} / \partial \delta\right)<0$, (ii) if $\theta \in$ $(0,(1 / 2))$, then $\left(\partial V_{M}^{D^{*}} / \partial \delta\right)<0$ when $\delta<(1 /(3-2 \theta))$ and $\left(\partial V_{M}^{D^{*}} / \partial \delta\right)>0$ when $\delta>(1 /(3-2 \theta))$

(d) (i) If $\theta \in((1 / 4)(7-\sqrt{13}), 1)$, then $\left(\partial V_{S C}^{D^{*}} / \partial \delta\right)<0$, (ii) if $\theta \in(0,(1 / 4)(7-\sqrt{13}))$, then $\left(\partial V_{S C}^{D^{*}} / \partial \delta\right)<0$ when $\delta<\delta_{1}$ and $\left(\partial V_{S C}^{D^{*}} / \partial \delta\right)>0$ when $\delta>\delta_{1}$, where $\delta_{1}=\left(\begin{array}{ll}\left(9-9 \theta+2 \theta^{2}-(3-2 \theta) \quad \sqrt{9-14 \theta+5 \theta^{2}}\right) /\end{array}\right.$ $\left.2\left(9-12 \theta+4 \theta^{2}\right)\right)$

Proof. See Appendix D. Corollary 2(a) depicts the impacts of the manufacturer's altruistic distributional fairness on the pricing decisions in decentralized case. When placing a higher altruistic fairness, the manufacturer cares more about the retailer's distributional profit and thus charges a lower wholesale price. Consequently, the retailer pulls the retail price down. In addition, the wholesale price decreases faster than the retail price, resulting in a bigger markup for the retailer. Compared with Corollary 1(b), the altruistic fairness exhibited by the manufacturer poses an opposite effect on pricing decision compared to that of retailer's CSR concern level. Owing to a lower retail price, with the manufacturer exhibiting a heavier altruistic fairness, we can infer that the resulting demand increases as it is inversely related to retail price $\left(\left(\partial D^{D *} / \partial \delta\right)<0\right)$, and the retailer's CSR components thereby increase $\left(\left(\partial \operatorname{CSR}_{R}^{D^{*}} / \partial \delta\right)<0\right)$.

Corollary 2(b) uncovers the impacts of the manufacturer's altruistic fairness on the pure profits of the individuals and the channel. The manufacturer's pure profit decreases, and the retailer's pure profit increases with a higher altruistic fairness. This is because the increased profit owing to a larger resulting demand is much (less) to counterbalance the profit loss owing to the lower retail (wholesale) price for the retailer (manufacturer) (see Corollary 2(a)). Moreover, the increased pure profit of retailer is sufficient to compensate the pure profit loss of the manufacturer, leading to an increase in pure channel profit $\left(\left(\partial \pi_{\mathrm{SC}}^{D^{*}} / \partial \delta\right)>0\right)$. Corollary $2(\mathrm{~b})$ also shows that a higher altruistic fairness will increase the socially responsible profit of the retailer. Observe that $\left(\partial \operatorname{CSR}_{R}^{D^{*}} / \partial \delta\right)>0$, and the retailer's socially responsible profit clearly increases as both pure profit and CSR components of the retailer increase. Note that $\left(\partial \pi_{M}^{D^{*}} / \partial \delta\right)-\left(\partial \pi_{R}^{D^{*}} / \partial \delta\right)<0$, and it represents that the pure profit gap between the manufacturer and retailer is bridged when the manufacturer exhibits a bigger altruistic fairness on the retailer. To sum up, combined with Corollaries $1(\mathrm{~b})$ and $1(\mathrm{c})$, the socially responsible retailer (manufacturer) exhibits a heavier CSR concern level (altruistic fairness behavior) and will decrease the corresponding pricing decisions, decreasing his on pure profit but increasing the pure profits of his counterpart and the channel.

Corollary 2(c) shows the impact of the manufacturer's altruistic fairness on the socially responsible profit of the manufacturer, which is more complicated and relied on the CSR concern level. When CRS concern level is very big $\theta \in((1 / 2), 1)$, the manufacturer's socially responsible profit decreases with a bigger altruistic fairness. Otherwise, when CSR concern level is relatively small $\theta \in(0,(1 / 2))$, the manufacturer's socially responsible profit decreases if $\delta<(1 /(3-2 \theta))$ and increases if $\delta>(1 /(3-2 \theta))$. The impacts of the altruistic fairness on the socially responsible channel profit can be explained in a similar pattern, which is shown in Corollary 2(d) and is further elaborated herein.

4.3. The Comparisons of the Supply Chain Performance in Both Centralized and Decentralized Models. Based on Corollary 1 (a), the maximum and the minimum pure channel profit are thus obtained as $\max \pi_{\mathrm{SC}}^{C}=\left(T^{2} / 4 \beta\right)+\lambda K$ and $\min \pi_{\mathrm{SC}}^{C}=$ 0 when $\theta=0$ and $\theta=1$, respectively, in centralized case. However, the socially responsible channel profit clearly increases in $\theta$. It is obvious that the centralized channel obtains the maximum (minimum) pure channel profit and minimum (maximum) socially responsible channel profits when $\theta=0(\theta=1)$.

In the decentralized model, the pure channel profit increases with both CSR concern level and manufacturer's altruistic fairness. Specifically, when the retailer's pure profit maximizes $(\theta=0)$, and the manufacturer exhibits no altruistic fairness $(\delta=0)$, the channel obtains the least pure profit as $\pi_{\mathrm{SC}}^{D}=\left(3 T^{2} / 16 \beta\right)+\lambda K$. On the other hand, either the retailer is perfect socially responsible when $\theta=1$ or the manufacturer exhibits the altruistic fairness as $\delta=(1 / 2)$, and the maximum channel profit is achievable as $\max \pi_{\mathrm{SC}}^{D}=\left(T^{2} / 4 \beta\right)+\lambda K$. The maximum channel profit in decentralized model is thus as much as that in the centralized model. In line with this, we can address that $\min \pi_{\mathrm{SC}}^{C}<\min \pi_{\mathrm{SC}}^{D}<\max \pi_{\mathrm{SC}}^{D}=\max \pi_{\mathrm{SC}}^{C}$. Let $\theta_{C}$ and $\theta_{D}$, respectively, denote the CSR concern level placed by the central planner and the socially responsible retailer in centralized and decentralized cases; we further compare the channel profit in the two models with different CSR concern levels.

Corollary 3. In the centralized and decentralized models, the comparisons of pure channel profits are confirmed as follows:

(a) If $(2 / 3) \leq \theta_{C}<1$, then $\pi_{S C}^{C *}<\pi_{S C}^{D *}$

(b) If $0<\theta_{C}<(2 / 3)$, (i) then $\pi_{S C}^{C *}>\pi_{S C}^{D *}$ when $\theta_{C}<(2(1-$ $\left.\left.2 \delta-\theta_{D}+2 \delta \theta_{D}\right) /\left(3-5 \delta-2 \theta_{D}+4 \delta \theta_{D}\right)\right)$; (ii) $\pi_{S C}^{C *} \leq$ $\pi_{S C}^{D *}$ when $\theta_{C} \geq\left(2\left(1-2 \delta-\theta_{D}+2 \delta \theta_{D}\right) /(3-5 \delta-\right.$ $\left.\left.2 \theta_{D}+4 \delta \theta_{D}\right)\right)$

Proof. See Appendix E. Corollary 3 shows that these key parameters, i.e., $\theta_{C}, \theta_{D}$, and $\delta$, play important roles in the corresponding relations of pure channel profits in 
centralized and decentralized models. To be specific, when the weight on CSR of the central planner is excessive $\left((2 / 3) \leq \theta_{C}<1\right)$, the centralized model clearly enjoys fewer pure profits than the decentralized model. Otherwise, when the weight on CSR of the central planner is small $\left(0<\theta_{C}<(2 / 3)\right)$, the pure profit in centralized channel is more than that in the decentralized model if $\theta_{C}<\left(2\left(1+2 \delta-\theta_{D}-2 \delta \theta_{D}\right) /\left(3+5 \delta-2 \theta_{D}-4 \delta \theta_{D}\right)\right)$. Otherwise, the decentralized model obtains more pure profit than the centralized model if $\theta_{C}>\left(2\left(1+2 \delta-\theta_{D^{-}}\right.\right.$ $\left.\left.2 \delta \theta_{D}\right) /\left(3+5 \delta-2 \theta_{D}-4 \delta \theta_{D}\right)\right)$. Specifically, when $\theta_{C}=0$, namely, the centralized channel is a pure profit maximizer and thus obtains the maximum pure profit, the decentralized channel can achieve as much pure channel profit as that in the centralized case when $\theta_{D}=1$ or $\delta=(1 / 2)$.

Moreover, when the CSR concern levels are the same in both centralized and decentralized cases, that is, $\theta_{C}=\theta_{D}=\theta$, the boundary in Corollary 3 can be rewritten as $\theta^{*}=\left(\left(5-9 \delta-\sqrt{9-26 \delta+17 \delta^{2}}\right) / 2(2-4 \delta)\right)$. Due to $\delta \in(0,(1 / 2)), \theta^{*}$ decreases in $\delta$ and $\max \theta^{*}=(1 / 2)$. In other words, the decentralized channel achieves more pure profit than the centralized channel when $\theta>(1 / 2)$, and whether the decentralized channel achieves more pure profit depends on $\theta<(1 / 2)$ : the decentralized channel achieves more pure profit if $\theta>\left(\left(5-9 \delta-\sqrt{9-26 \delta+17 \delta^{2}}\right) / 2(2-4 \delta)\right)$ and not otherwise.

Specifically, when the manufacturer is distributionfairness-neutral $(\delta=0)$, we rearrange the boundary as $\theta_{C}=\left(2\left(1-\theta_{D}\right) /\left(3-2 \theta_{D}\right)\right)$; especially we have $\theta=(1 / 2)$ when $\theta_{C}=\theta_{D}=\theta$. In other words, the centralized channel achieves more pure profit than the decentralized case when $\theta<(1 / 2)$. Otherwise, it is much more for decentralized channel to obtain more pure profits than the centralized case when $\theta>(1 / 2)$.

\section{Optimal Carbon Cap-and-Trade Policy}

To obtain an appropriate carbon cap-and-trade policy, this section first investigates the optimal carbon trade price and then discusses the appropriate carbon cap for the government.

\subsection{An Appropriate Carbon Trade Price to Maximize Social} Welfare. In this subsection, the carbon cap-and-trade policy for the government is planned to seek a balance between the firm's profit and the social benefits. Consumer surplus and environmentally negative impacts are involved in the social benefits according to Pal and Saha [42]. In addition, due to the carbon cap-and-trade regulation, the surplus revenues or extra expenses $\lambda(e D-K)$ of the channel are transformed from one firm to another, thus exerting no impacts on the gross profit from the perspective of social welfare (SW), which will be absent in the objective function of social welfare. Hence, the objective function of social welfare for the government includes firm's sales profit, consumer surplus, and environmental impact, which is shown as follows:

$$
\mathrm{SW}=(p-c)(a-\beta p)+\frac{(a-\beta p)^{2}}{2 \beta}-d(a-\beta p) .
$$

The first term in equation (16) is the gross profit by selling the product, the second term gauges the consumers surplus, and the last one measures environmental impacts caused by producing and selling products. Referring to Mäler [51], Richard [52], we assume that the coefficient $d>e>0$ referred to how it is environmentally damaging for the product, such as resources consumption and waste emission in product-manufacturing process, pollution and energy utilization in working, and recycling in end-lifecircle, with a higher $d$ suggesting a more environmentally damaged product. The environmental damage of the product is evaluated by the government and is thus a private information of the government.

Proposition 4. The optimal carbon trade price $\lambda$ is confirmed to maximize the social welfare in the centralized and decentralized cases, which is given by $\lambda^{\mathrm{C*}}=((d \beta(2-\theta)-$ $(a-\beta c)(1-\theta)) / e \beta)$

$\lambda^{D *}=\left(\left(2 d \beta M_{1}-(a-\beta c) M_{3}\right) / e \beta(1-\delta)\right)$.

Proof. See Appendix F. Proposition 4 reveals the optimal carbon trade prices to maximize social welfare for the government, which relies largely on the different models. The social welfare first increases (e.g., $0<\lambda^{C}<((d \beta(2-\theta)-(a-\beta c)(1-\theta)) / e \beta)$ in centralized model and $0<\lambda^{D}<\left(\left(2 d \beta M_{1}-(a-\beta c) M_{3}\right) / e \beta(1-\delta)\right)$ in decentralized model) with a high carbon trade price and then decreases (e.g., $\lambda^{C}>((d \beta(2-\theta)-(a-\beta c)(1-\theta)) / e \beta)$ in centralized model and $\lambda^{D}>\left(\left(2 d \beta M_{1}-(a-\beta c) M_{3}\right) /\right.$ $e \beta(1-\delta))$ in decentralized model). Therefore, the optimal carbon trade prices for government to maximize the social welfare hold when $\lambda^{C *}=((\beta d(2-\theta)-(a-\beta c)(1-\theta)) / \beta e)$ in the centralized model and $\lambda^{D}=\left(\left(2 d \beta M_{1}-\right.\right.$ $\left.\left.(a-\beta c) M_{3}\right) / e \beta(1-\delta)\right)$ in the decentralized model.

The optimal carbon trade prices are contingent upon a series of coefficients such as $d, \theta$, and $\delta$. Obviously, the optimal carbon trade price increases in $d$, signifying a more environmentally damaging product stimulating the carbon trade price. It is understandable that the government encourages (restrict) those environmentally friendly (environmentally damaging) products by implementing a lower (higher) carbon trade price. In addition, given that $\left(\partial \lambda^{C *} / \partial \theta\right)=(G / e \beta)>0 \quad$ and $\left(\partial \lambda^{D *} / \partial \theta\right)=$ $(2 G(1-2 \delta) / e \beta(1-\delta))>0$, the integrated and decentralized supply chain will confront a higher carbon trade price if the retailer plays a heavier weight on CSR in this carbon capand-trade policy. This is because a heavier weight on CSR generates more resulting demand (see Corollaries 1(a) and 1(b)) and then exerts more serious impacts on environment, which finally leads to a restricted carbon trade price determined by the government. Computing $\left(\partial \lambda^{D *} / \partial \delta\right)=\left(2 G(1-\theta) / e \beta(1-\delta)^{2}\right)>0$ yields that the government increases carbon trade price when the manufacturer cares more about the altruistic fairness to the retailer. The decentralized channel obtains the minimum 
carbon trade price with both lowest fairness and CSR concern level.

Substituting $\lambda_{C *}$ and $\lambda_{D *}$ into the equilibrium strategies of the supply chain yields Table 3 . Without the loss of generality, we assume $G=a-\beta c-\beta d>0$, that is, $0<d<(a / \beta)-c$, and the environmental impact (from the perspective of the government) must be less than the difference between the price cap $(a / \beta)$ and unit cost $c$ (from the view of the supply chain). In other words, it is not profitable for the government to support those products when its unit makeup of the channel can not compensate the environmental damage. The retail price attains same in both centralized and decentralized cases as $p^{C *}=p^{D *}=c+d$, resulting in the same resulting demand and CSR as $D^{C *}=D^{D *}=G$ and $\mathrm{CSR}^{C *}=\operatorname{CSR}^{D *}=(\theta G / 2 \beta)$. The centralized and decentralized models exhibit the same retail price and resulting demand in this kind of carbon trade price, signifying that the product selling market is eventually controlled by the government rather than the socially responsible channel.

We can then address $S W^{C *}=S W^{D *}=\left(G^{2} / 2 \beta\right)$ by substituting $p^{C *}$ and $p^{D *}, D_{C *}$ and $D_{D *}$ into equation (16). The social welfare for the government is the same in the centralized and decentralized channels and equal to consumer surplus. The reason behind this result lies in that the environmental damage concerned by the government is exactly compensated by the unit makeup owned by the channel when manufacturing each product. Although the carbon trade price is absent in the objective function of social welfare, it can indirectly affects social welfare by directly affecting the pricing decision and resulting demand. Moreover, the social welfare decreases in an increasing $d$, implying that a more environmentally damaging product pulls down the social welfare.

In this carbon trade price policy, the pricing decision and resulting demand in product market in the centralized and decentralized cases are the same. However, observe that the differences lie in $\lambda(K-e D)$ for a given $K$, and the performance in centralized case is still different from that in the decentralized case. Interestingly, we can find that the differences between centralized and decentralized cases rely on carbon trading market $(\lambda(K-e D))$ rather than product selling market $((p-c) D)$ by applying such a carbon trade price policy. This carbon trade policy thereby helps the government regulate and control product selling market (including pricing and resulting demand) possible.

To sum up, the government applies the different carbon trade prices but obtains same social welfare in both the centralized and decentralized channels by maximizing the social welfare. The product selling market (including pricing and resulting demand) stays the same, while the carbon trade market is different in centralized and decentralized cases. The best carbon trade prices increase in coefficients $d$, $\theta$, and $\delta$.

5.2. A Feasible Carbon Cap for the Government. In this section, we shall next investigate an appropriate carbon cap for the government. Given that the objective function of
Table 3: The equilibrium strategies in Models $C$ and $D$ in this carbon cap-and-trade policy.

\begin{tabular}{lcccc}
\hline & $w$ & $p$ & $D$ & CSR \\
\hline Model $C$ & N/A & $c+d$ & $G$ & $\theta G^{2} / 2 \beta$ \\
Model $M$ & $(a-(2-\theta) G) / \beta$ & $c+d$ & $G$ & $\theta G^{2} / 2 \beta$ \\
\hline
\end{tabular}

government is to maximize social welfare, and the carbon cap exerts no impacts on social welfare, which is shown in equation (16), therefore, the government is not able to determine a carbon cap by maximizing the social welfare. Meanwhile, from the view of the channel by maximizing the channel performance, it is also impossible to formulate a carbon cap as shown in Section 5.1. Note that the carbon trade price is first attainable for the government to maximize the social welfare. This paper proposes a novel principle to regulate the carbon cap, that is, guaranteeing the channel to obtain as many pure profits as the case when the cap-andtrade regulation is not implemented. We define this principle as a two-stage carbon cap-and-trade policy. Specifically, the government first determines the carbon trade price to maximize social welfare and then decides a carbon cap to make the pure channel profit intact for the whole supply chain.

Applying this two-stage carbon cap-and-trade policy, we formulate the optimal carbon cap across the two different models, which is shown in Proposition 5.

Proposition 5. The feasible carbon caps are determined as $K^{C *}=\left(e(1-\theta)((a-\beta c)(3-\theta)-\beta d(2-\theta)) /(2-\theta)^{2}\right)$ and $K^{D *}=\left(e M_{3}\left((a-c \beta) M_{5}-2 d \beta M_{1}\right) / 4 M_{1}^{2}\right)$ in centralized and decentralized cases, respectively.

Proof. See Appendix G. Proposition 5 reveals the feasible carbon cap for the government in two different models. Obviously, the carbon cap decreases in $d$, suggesting that the government will implement a stricter carbon cap when the supply chain produces and sells a more environmentally damaging product. Additionally, in centralized case, the carbon cap decreases in $\theta$ as $\left(\partial K^{C *} / \partial \theta\right)<0$, and in decentralized case, the impacts of the altruistic distributional fairness and CSR concern level are more complex. In more detail, the carbon cap decreases in $\theta$ when $\theta>((d \beta)$ $3 \delta)-(a-\beta c)(1-\delta)) / d \beta(1-2 \delta))$ and increases in $\theta$ when $\theta<((d \beta(2-3 \delta)-(a-\beta c)(1-\delta)) / d \beta(1-2 \delta))$. For the altruistic distributional fairness, the carbon cap increases with an excessive altruistic distributional fairness as $\delta<((d \beta(2-\theta)-a+c \beta) /(a-c \beta-d \beta(3-2 \theta)))$ and decreases with a corresponding low one when $\delta>((d \beta(2-\theta)-a+c \beta) /(a-c \beta-d \beta(3-2 \theta)))$.

To further prove the feasibility of this carbon cap policy, it should be guaranteed that some firms buy the insufficient carbon cap, and the others sell the surplus carbon quotas from the carbon trading system, which makes the carbon trading market trade successfully. Observe that $\theta \in[0,1]$ and $0<d<(a / \beta)-c$, and comparing $K$ with $e D$ in different models yields that if $(((a / \beta)-c) /(2-\theta))<d<(a / \beta)-c$ $\left(\left((a-c \beta)(1-\delta) / 2 \beta M_{1}\right)<d<(a / \beta)-c\right)$, then $K^{C *}>e D^{C *}$ 


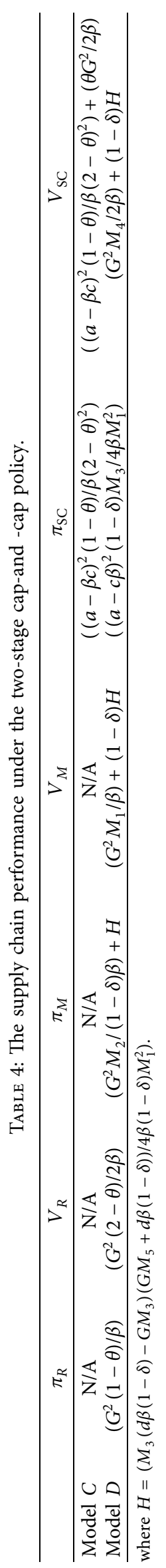


$\left(K^{D *}>e D^{D *}\right)$; namely, the socially responsible centralized (decentralized) channel will sell the extra carbon caps. Otherwise, if $0<d<(((a / \beta)-c) /(2-\theta))(0<d<((a-c \beta)$ $\left.\left.(1-\delta) / 2 \beta M_{1}\right)\right)$, then $K^{C *}<e D^{C *}\left(K^{D *}<e D^{D *}\right)$; namely, the socially responsible centralized (decentralized) channel should buy the surplus carbon quotas. This carbon cap principle thereby proves to be applicable in practice.

Substituting $K^{C *}$ and $K^{D *}$ into the performances of the supply chain and its members yields Table 4 .

This subsection shall next explore the effects of key parameters on the supply chain performance in this twostage cap-and-trade regulation. Firstly, in the centralized case, the pure channel profit always decreases, and the socially responsible profit increases when $\left(G^{2} / 2(a-c \beta)^{2}\right)>\left(\theta /(2-\theta)^{3}\right)$, while it decreases when $\left(G^{2} / 2(a-c \beta)^{2}\right)<\left(\theta /(2-\theta)^{3}\right)$ with a heavier CSR concern level. In the decentralized case, the impacts of CSR concern level $\theta$ and the altruistic distributional fairness $\delta$ on the supply chain performance are more complicated, which is shown in Section 6 by numerical analysis.

\section{Numerical Experiment}

This paper first explores the impacts of a pair of parameters $\theta$ and $\delta$ on the pure profits of the channel as well as the individuals under this two-stage carbon cap-and-trade policy. Next, by following the existing literature $[47,53-55]$ and setting $a=1, \beta=0.5, c=0.4$, and $d=1.2$, Figures $1-3$ graphically reveal how the altruistic distributional fairness and CSR concern level affect the pure profits of the channel, the manufacturer, and the retailer, respectively.

Initially, the pure channel profit in the decentralized model increases with an increasing altruistic fairness concern and CSR concern level, while the pure channel profit in the centralized model decreases with a high CSR concern level. Figure 1 also indicates that the channel can achieve the maximum pure profit when either the retailer is completely CSR-concerned $(\theta=1)$ or the manufacturer exhibits a altruistic fairness concern at $\delta=(1 / 2)$, which is shown in Corollary 3 . The maximum pure channel profit in the decentralized case is the same as that in the pure-profitmaximizing centralized channel $(\theta=0)$. On the other hand, the minimum pure channel profit holds at both $\delta=0$ and $\theta=0$. This signifies that the socially responsible behavior (CSR concern by the retailer or the altruistic fairness concerned by the manufacturer) can really generate economic benefits in this two-stage carbon cap-andtrade policy. Moreover, the pure channel profit in the centralized scenario decreases with an increasing $\theta$. Figure 1 graphically shows that the decentralized channel achieves more pure profit than the centralized case when $\theta>(1 / 2)$ no matter how much the manufacturer cares about the altruistic fairness. Otherwise, whether the centralized channel obtains more pure profit than the decentralized case depends on the manufacturer's altruistic fairness concern when $\theta<(1 / 2)$. It signifies that the relative relations of pure channel profit in two different models still hold in this two-stage carbon cap-and-trade regulation.

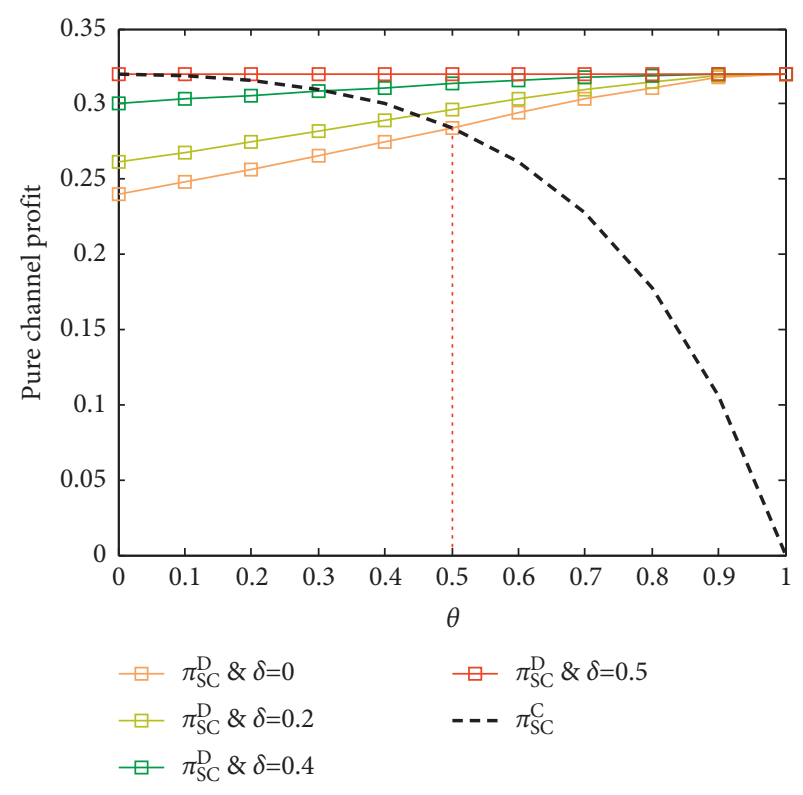

FIgURE 1: The joint impacts of $\delta$ and $\theta$ on the pure channel profit.

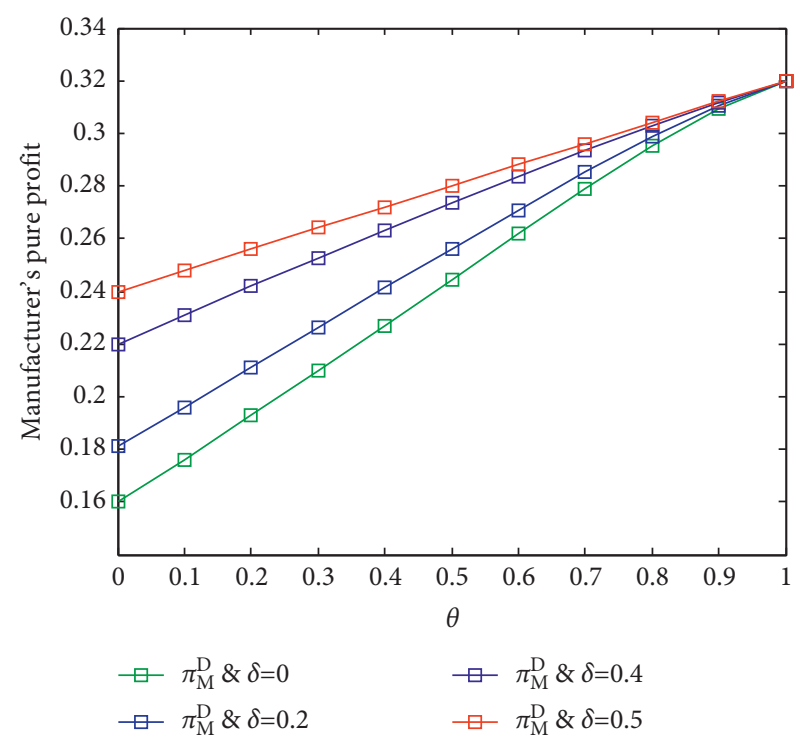

Figure 2: The joint impacts of $\delta$ and $\theta$ on the manufacturer's pure profit.

Similarly, both CSR concern level $\theta$ and the altruistic fairness concern $\delta$ exert a positive impact on manufacturer's pure profit. In more detail, the manufacturer achieves the minimum pure profit when both $\theta=0$ and $\delta=0$. Under a given $\theta(\delta)$, the pure profit of the manufacturer increases with $\delta(\theta)$. The manufacturer's pure profit reaches the peak when $\theta=1$ with the same pure profit as much as that of the whole channel, signifying that the retailer gives up all the pure profit in this case.

Next, we explore the impacts of a pair of parameters $\theta$ and $\delta$ on the socially responsible profit of the channel in two different cases under this two-stage carbon cap-and-trade policy. Regarding socially responsible profit, Figure 3 shows 


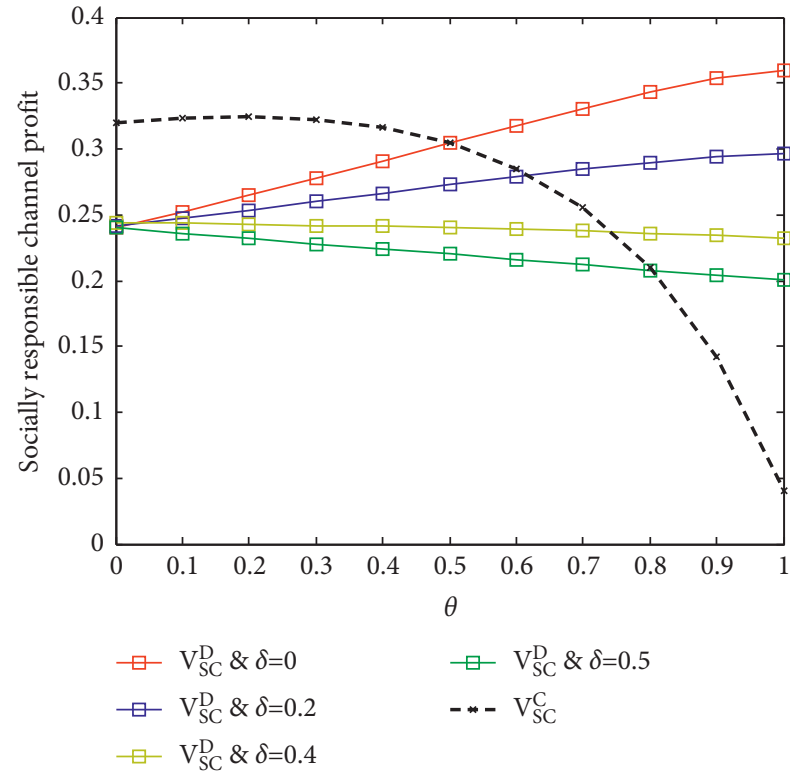

FIGURE 3: The joint impacts of $\delta$ and $\theta$ on the socially responsible channel profit.

that the centralized model achieves fewer socially responsible profits when the CSR concern level is relatively high. Compared with Figure 1, in the centralized model, a heavier CSR concern level decreases the pure channel profit more but increases less on CSR component, thereby decreasing the socially responsible channel profit. In the term of the decentralized case, the socially responsible channel profit decreases in altruistic fairness concern $\delta$, while the impact of $\theta$ on the socially responsible channel profit is more complicated and relies on $\delta$. Specifically, it increases the socially responsible channel profit when $\delta$ is relatively small. Otherwise, the socially responsible channel profit will decrease when $\delta$ is excessive with an increasing $\theta$.

In short, applying this two-stage carbon cap-and-trade regulation, the government first determines an optimal carbon trade price to maximize social welfare. A carbon cap then is determined for each firm to ensure that the channel obtains the same profit with the case when the carbon capand-trade policy is not implemented. The government determines different carbon cap and carbon trade price, respectively, for the centralized and decentralized cases. It is found that the coefficients $d, \delta$, and $\theta$ affect the carbon capand-trade policy (including carbon trade price and carbon cap) and guarantee the proposed two-stage carbon cap-andtrade policy feasibility in the carbon trading market.

\section{Implications, Conclusion, and Future Research}

7.1. Implications. The conventional hypothesis for maximizing pure profit is far away from perfect. This paper constructs a socially responsible supply chain in the context of carbon cap-and-trade mechanism. Specifically, we consider a socially responsible supply chain, in which the retailer is CSR-concerned, and the manufacturer exhibits the altruistic fairness concern. The main managerial implications of this paper are twofold and presented as follows:

Firstly, this paper tells that taking CSR will not always decrease the profitability of the supply chain but increase the supply chain performance in the decentralized model. In more detail, placing a heavier weight on CSR for the retailer will decrease his own profit but greatly increase the manufacturer's profit, therefore enhancing the channel profit. The centralized channel and the decentralized channel have no essential differences in the pure profit when the socially responsible retailer places an appropriate CSR concern level. In terms of the manufacturer's socially responsible behavior, an increase in the altruistic fairness concern for the manufacturer will clearly increase the retailer's pure profit but decrease the manufacturer's profit. Furthermore, the impacts of the altruistic fairness concern on the socially responsible profits of the supply chain and its members are more complicated and relied largely on the CSR concern levels.

Secondly, this paper proposes a novel two-stage carbon cap-and-trade policy for the government regulator and proves its feasibility in carbon trading system. To be specific, the government first determines the carbon trade price to maximize social welfare and then sets a carbon cap to make the pure channel profit intact for the whole supply chain compared to the case when the carbon cap-and-trade regulation is not implemented. By applying this two-stage carbon cap-and-trade regulation, the government applies the different carbon trade prices but obtains the same social welfare in both the centralized and decentralized channels by maximizing the social welfare. In addition, the product selling market performs the same, while the carbon trading market exhibits differently in the supply chain, which helps the government regulate and control product selling market possible by determining appropriate carbon cap-and-trade policy.

7.2. Conclusions. This paper investigates the different socially responsible behaviors under the carbon cap-and-trade regulation in a socially responsible chain. The equilibrium decisions and performances in the centralized and decentralized models are confirmed, analyzed, and compared. The main conclusions are as follows:

7.2.1. For CSR Concern Level. The socially responsible retailer concerning more CSR will decrease his own pure profit but increase the pure profits of his counterpart and the channel. When the retailer places a full weight on CSR as $\theta=1$, the decentralized channel can achieve the maximum pure profits as many as those in the centralized model. This result shows that taking CSR will not always harm the supply chain profit but stimulate economic benefits under certain conditions.

7.2.2. For Distributional Fairness. Parallel to CSR, the socially responsible manufacturer will decrease his own pure profit but increase the pure profits of his counterpart and the 
channel profit when exhibiting a heavier altruistic fairness concern. When the manufacturer exhibits the altruistic fairness concern at $\delta=(1 / 2)$, the decentralized channel achieves the maximum pure channel profit as much as that in a pure profit-maximizing centralized case. This result implies that the altruistic fairness concern plays a key role in distributing the profits between the manufacturer and the retailer in such a socially responsible supply chain.

7.2.3. For Governmental Policy on Carbon Cap-and-Trade. Determining a carbon trading price to maximize the social welfare, this paper proposes a novel two-stage carbon capand-trade policy for the government, in which the carbon cap is determined to confirm that the supply chain obtains the same pure profits when not implementing the carbon emission policy. It is interestingly to find that the differences between the centralized and decentralized models are exhibited in the carbon trading market rather than the product selling market, more that previous studies did, which makes the government regulates and controls the product selling market possible by determining the appropriate carbon policy.

7.3. Future Research. Although this paper investigates how the different socially responsible behaviors of the supply chain individuals affect the operational decisions and supply chain performance, several limitations and future researching directions hold in the current work. Firstly, our current work gauges CSR performance for a socially responsible individual by adopting consumer surplus as a proxy of CSR concerns. The first potential extension of this paper would be to explore CSR investments for any socially responsible individual. Secondly, this paper considers the operational decisions under the carbon cap-and-trade regulation. An interesting and changing topic regarding this paper would be studying the other carbon regulations (i.e., emission constraint or carbon tax mechanism). Then, it would be an interesting theme to investigate the impacts of some key factors (i.e., selling effort, sustainability innovation, and green degree) on the market demand, as this paper only considers a linear demand. Lastly, the government regulators may pose different weights on economic profits and social benefits when they determine such carbon policy. Therefore, it is valuable to investigate and determine a feasible carbon regulation policy for the government by playing different weights on firms' profits, consumer surplus, and environmental damage.

\section{Appendix}

\section{A. Proof of Propositions 1 and 2}

In Model $D$, in the second decision stage, the Stackelberg follower and retailer give the reaction function of retail price by solving equation (5): $\quad p^{*}=(a / \beta)-(T(1-\delta) /$ $2 \beta(2-\theta-\delta(3-2 \theta)))$. In the first decision stage, substituting $p^{*}$ into equation (7) yields the Stackelberg leader and manufacturer's wholesale price as $w^{D *}=((a)$ $\theta-\delta(4-3 \theta))+\beta(1-\delta)(2-\theta)$

$(c+e \lambda)) / 2 \beta(2-\theta-\delta(3-2 \theta)))$. It can be rewritten as $w^{D *}=(a / \beta)-(T(1-\delta)(2-\theta) / 2 \beta(2-\theta-\delta(3-2 \theta)))$. We then have the expression of $p^{D *}$ by substituting $w^{D *}$ into $p^{*}$. Then, substituting $w^{D *}$ and $p^{D *}$ into equations (4)-(7) yields the performance of the channel and the individuals.

The proof of Propositions 1 and 2 is thus completed.

\section{B. Proof of Proposition 3}

According to equation (11), we can derive $\left(\partial^{2} V_{\mathrm{SC}}^{C} / \partial p^{2}\right)=-(2-\theta) \beta<0$. Therefore, $V_{\mathrm{SC}}^{C}$ is concave in $p$. Applying the first-order condition $\left(\partial V_{\mathrm{SC}}^{C} / \partial p\right)=0$ yields the retail price: $p^{C *}=(a / \beta)-(T / \beta(2-\theta))$. Substituting $p^{C *}$ into $V_{\mathrm{SC}}^{\mathrm{C}}$ gives Proposition 3 .

\section{Proof of Corollary 1}

According to Propositions 1-3, taking the first-order derivative of optimal pricing decisions and the performance of the individual and the channel with regard to $\theta$, respectively, we address $\left(\partial p^{C *} / \partial \theta\right)=-\left(T / \beta(2-\theta)^{2}\right)<0, \quad\left(\partial \pi_{\mathrm{SC}}^{C *} / \partial \theta\right)=$ $-\left(T^{2} \theta / \quad \beta(2-\theta)^{3}\right)<0, \quad$ and $\quad\left(\partial V_{\mathrm{SC}}^{C *} / \partial \theta\right)=\left(T^{2} / 2 \beta\right.$ $\left.(2-\theta)^{2}\right)>0 ;\left(\partial w^{D *} / \partial \theta\right)=-\left(\delta(1-\delta) T / 2 \beta M_{1}^{2}\right)<0,\left(\partial p^{D *} /\right.$ $\partial \theta)=-\left((1-\delta)(1-2 \delta) T / 2 \beta M_{1}^{2}\right)<0,\left(\partial \pi_{R}^{D^{*}} / \partial \theta\right)=-\left(T^{2}(1-\right.$ $\left.\delta)^{2}(\delta(1-2 \theta)+\theta) / 4 \beta M_{1}^{3}\right), \quad\left(\partial V_{R}^{D^{*}} / \partial \theta\right)=\left(T^{2} \quad(1-\delta)^{2}\right.$ $\left.(2-\theta-\delta(5-2 \theta)) / 8 \beta M_{1}^{3}\right),\left(\partial \pi_{M}^{D^{*}} / \partial \theta\right)=\left(T^{2}(1-\delta)(2-\theta-\right.$ $\left.\left.\delta \quad(7-5 \theta)+\delta^{2}(7-6 \theta)\right) / 4 \beta M_{1}^{3}\right), \quad\left(\partial V_{M}^{D^{*}} / \partial \theta\right)=\left(T^{2}\right.$ $\left.(1-2 \delta)(1-\delta)^{2} / 4 \beta M_{1}^{2}\right), \quad\left(\partial \pi_{\mathrm{SC}}^{D^{*}} / \partial \theta\right)=\left((1-\delta)(1-2 \delta)^{2} T^{2}\right.$ $\left.(1-\theta) / 2 \beta M_{1}^{3}\right), \quad$ and $\left(\partial V_{\mathrm{SC}}^{D^{*}} / \partial \theta\right)=\left(T^{2}(1-\delta)^{2}\right.$ $\left.\left(3(2-\theta)+4 \delta^{2}(3-2 \theta)-\delta(19-10 \theta)\right) / 8 \beta M_{1}^{3}\right)$. Due to $\theta \in[0,1]$ and $\delta \in[0,(1 / 2))$, we can address that $\left(\partial \pi_{R}^{D^{*}} / \partial \theta\right)<0,\left(\partial \pi_{M}^{D^{*}} / \partial \theta\right)>0,\left(\partial V_{M}^{D^{*}} / \partial \theta\right)>0,\left(\partial \pi_{\mathrm{SC}}^{D^{*}} / \partial \theta\right)>0$, $\left(\partial V_{\mathrm{SC}}^{D^{*}} / \partial \theta\right)>0$, and $\left(\partial V_{R}^{D^{*}} / \partial \theta\right)$ is dependable.

The proof of Corollary 1 is thus completed.

\section{Proof of Corollary 2}

Similarly, taking the first-order derivative of optimal pricing decisions and the performance of the individual and the channel with regard to $\delta$, respectively, we can then address that $\left(\partial w^{D *} / \partial \delta\right)=-\left(T(2-\theta)(1-\theta) / 2 \beta M_{1}^{2}\right)<0, \quad\left(\partial p^{D *} / \partial \delta\right)=$ $-\left((1-\theta) T / 2 \beta M_{1}^{2}\right)<0, \quad\left(\partial \pi_{M}^{D^{*}} / \partial \delta\right)=-\left(T^{2} \delta(1-\theta)^{2} /\right.$ $\left.2 \beta M_{1}^{3}\right)<0, \quad\left(\partial \pi_{R}^{D^{*}} / \partial \delta\right)=\left(T^{2}(1-\delta)(1-\theta)^{2} / 2 \beta M_{1}^{3}\right)>0$, $\left(\partial V_{M}^{D^{*}} / \partial \delta\right)=-\left((1-\delta) \quad(1-\delta(3-2 \theta)) T^{2} / 4 \beta M_{1}^{2}\right)-\lambda K$, $\left(\partial V_{R}^{D^{*}} / \partial \delta\right)=\left(T^{2}(1-\delta)(2-\theta)(1-\theta) / 4 \beta M_{1}^{3}\right)>0, \quad\left(\partial \pi_{\mathrm{SC}}^{D^{*}} /\right.$ $\partial \delta)=\left((1-2 \delta)(1-\theta)^{2} T^{2} / 2 \beta M_{1}^{3}\right)>0, \quad$ and $\left(\partial V_{\mathrm{SC}}^{D^{*}} / \partial \delta\right)=$ $-\left((1-\delta) \quad\left(\delta^{2}(3-2 \theta)^{2}+(2-\theta) \theta-\delta\left(9-9 \theta+2 \theta^{2}\right)\right) T^{2} /\right.$ $\left.4 \beta M_{1}^{3}\right)-K \lambda$.

To simplify this, we let $\lambda=0$ and easily address $\delta=$ $(1 /(3-2 \theta))$ by solving $\left(\partial V_{M}^{D^{*}} / \partial \delta\right)=0$, and $\delta=((9-9 \theta+$ $\left.\left.2 \theta^{2}-(3-2 \theta) \sqrt{9-14 \theta+5 \theta^{2}}\right) / 2\left(9-12 \theta+4 \theta^{2}\right)\right)$ by solving $\left(\partial V_{\mathrm{SC}}^{D^{*}} / \partial \delta\right)=0$. Due to $\theta \in[0,1]$ and $\delta \in[0,(1 / 2))$, the proof of Corollary 2 is thus formulated.

\section{E. Proof of Corollary 3}

To compare the channel profit in the centralized and decentralized cases, we have $\theta_{C 1}=-\left(2\left(1-\theta_{D^{-}} 2 \delta+\right.\right.$ 
$\left.\left.2 \delta \theta_{D}\right) /(1-\delta)\right)$ and $\theta_{C 2}=\left(2\left(1-2 \delta-\theta_{D}+2 \delta \theta_{D}\right) /(3-5 \delta-\right.$ $\left.\left.2 \theta_{D}+4 \delta \theta_{D}\right)\right)$ by solving $\pi_{\mathrm{SC}}^{C}=\pi_{\mathrm{SC}}^{D}$. Due to $\theta_{C}, \theta_{D} \in[0,1]$ and $\delta \in[0,(1 / 2))$, we clearly have $\theta_{C 1}<0$ and $\theta_{C 1}$ can thus be eliminated. In addition, $\theta_{C 2}$ decreases in both $\theta_{D}$ and $\delta$. The minimum $\theta_{C 2}$ holds as $\min \theta_{C 2}=0$ when $\theta_{D}=1$ and $\delta=(1 / 2)$, while the maximum $\theta_{C 2}$ holds as $\max \theta_{C 2}=(2 / 3)$ when $\theta_{D}=0$ and $\delta=0$.

The proof of Corollary 3 is herein completed.

\section{F. Proof of Proposition 4}

Substituting $p^{C *}$ into equation (15), we can obtain the social welfare in Model $\mathrm{C} \mathrm{SW} \mathrm{SW}_{C}=((\beta(-c+2 d(-2+\theta)+e \lambda)+$ $\left.a(3-2 \theta)-2 c \beta(1-\theta)) / 2 \beta(2-\theta)^{2}\right) T$. After taking the firstorder and first-order derivatives of SW with regard to $\lambda$, we have $\lambda=((d \beta(2-\theta)-(a-\beta c)(1-\theta)) / e \beta)=\lambda^{C *} \quad$ and $\left(\partial^{2} \mathrm{SW}_{C} / \partial \lambda^{2}\right)=-\left(e^{2} \beta /(2-\theta)^{2}\right)<0$. Accordingly, $\mathrm{SW}_{C}$ increases in $\lambda$ if $\lambda<\lambda^{C *}$, while decreases in $\lambda$ if $\lambda>\lambda^{C *}$. Similarly, we can obtain $\lambda^{D *}=\left(\left(2 d \beta M_{1}-(a-\beta c) M_{3}\right) /\right.$ $e \beta(1-\delta))$ in the decentralized model.

Proposition 4 is thus completed.

\section{G. Proof of Proposition 5}

Note that $\pi_{\mathrm{SC}}^{N}=(p-c)(a-\beta p), \pi_{\mathrm{SC}}^{N}$ can be regarded as a special case of $\pi_{\mathrm{SC}}$, and $\pi_{\mathrm{SC}}^{*}$ is equivalent to $\pi_{\mathrm{SC}}^{N *}$ when $\lambda=0$ and $K=0$. Accordingly, we get the carbon cap $K^{C *}=(e(1-$ $\left.\theta)(2 a-2 \beta c-\beta \lambda e) / 2(2-\theta)^{2}\right)$ and $K^{D}=(e(2 a-2 \beta c-\beta \lambda e)$ $\left.(1-\delta) M_{3} / 4 M_{1}^{2}\right)$ by solving $\pi_{\mathrm{SC}}^{C}=\pi_{\mathrm{SC}}^{N}$ and $\pi_{\mathrm{SC}}^{D}=\pi_{\mathrm{SC}}^{N}$, respectively. Substituting $\quad \lambda^{C *}=((d(2-\theta)-(a-\beta c)$ $(1-\theta)) / e \beta)$ and $\lambda^{D *}=\left(\left(2 d \beta M_{1}-(a-\beta c) M_{3}\right) / e \beta(1-\delta)\right)$ into $K^{C}$ and $K^{D}$, we can address $K^{C *}=(e(1-\theta) \quad((a-$ $\left.\beta c)(3-\theta)-\beta d(2-\theta)) /(2-\theta)^{2}\right) \quad$ and $\quad K^{D *}=\left(e M_{3}\right.$ $\left.\left((a-c \beta) M_{5}-2 d \beta M_{1}\right) / 4 M_{1}^{2}\right)$ in the centralized and decentralized models, respectively.

Proposition 5 is thus completed.

\section{Data Availability}

No data were used to support this study.

\section{Conflicts of Interest}

The authors declare that they have no conflicts of interest.

\section{Acknowledgments}

This paper was strongly supported by the National Social Science Fund of China (Grant no. 19BGL095).

\section{References}

[1] M. Gong, Y. Gao, L. Koh, C. Sutcliffe, and J. Cullen, "The role of customer awareness in promoting firm sustainability and sustainable supply chain management," International Journal of Production Economics, vol. 217, pp. 88-96, 2019.

[2] Y. Fu, R. A. Kok, B. Dankbaar, P. E. Ligthart, and A. C. van Riel, "Factors affecting sustainable process technology adoption: a systematic literature review," Journal of Cleaner Production, vol. 205, pp. 226-251, 2018.

[3] A. Atasu and G. C. Souza, "How does product recovery affect quality choice?" Production and Operations Management, vol. 22, no. 4, pp. 991-1010, 2013.

[4] L. Liu, C. Chen, Y. Zhao, and E. Zhao, "China's carbonemissions trading: overview, challenges and future," Renewable and Sustainable Energy Reviews, vol. 49, pp. 254-266, 2015.

[5] N. M. Modak, S. Panda, S. S. Sana, and M. Basu, "Corporate social responsibility, coordination and profit distribution in a dual-channel supply chain," Pacific Science Review, vol. 16, no. 4, pp. 235-249, 2014.

[6] X. Chang, H. Xia, H. Zhu, T. Fan, and H. Zhao, "Production decisions in a hybrid manufacturing-remanufacturing system with carbon cap and trade mechanism," International Journal of Production Economics, vol. 162, pp. 160-173, 2015.

[7] C. Böhringer, "Two decades of European climate policy: a critical appraisal," Review of Environmental Economics and Policy, vol. 8, no. 1, pp. 1-17, 2014.

[8] J. J. Zhang, T. F. Nie, and S. F. Du, "Optimal emission-dependent production policy with stochastic demand," International Journal of Society Systems Science, vol. 3, no. 1, pp. 21-39, 2011.

[9] S. Du, L. Hu, and L. Wang, "Low-carbon supply policies and supply chain performance with carbon concerned demand," Annals of Operations Research, vol. 255, no. 1-2, pp. 569-590, 2017.

[10] N. M. Modak, S. Panda, and S. S. Sana, "Pricing policy and coordination for a two-layer supply chain of duopolistic retailers and socially responsible manufacturer," International Journal of Logistics Research and Applications, vol. 19, no. 6, p. 22, 2016.

[11] D. Ni and K. W. Li, "A game-theoretic analysis of social responsibility conduct in two-echelon supply chains," International Journal of Production Economics, vol. 138, no. 2, pp. 303-313, 2012.

[12] "Price waterhouse coopers," 2010, http://www.pwc.com/ca/ en/sustainability/publications/csr-trends-2010-09.pdf.

[13] KPMG, 2008. http://www.kpmg.eu/docs/Corp_ responsibility_Survey_2008.pdf.

[14] Merrick, "GAP offers unusual look at factory conditions: fighting sweatshop tag retailer detail problems among thousands of plants," Wall Street Journal, vol. A1, 2004.

[15] S. Panda, "Coordination of a socially responsible supply chain using revenue sharing contract," Transportation Research Part E: Logistics and Transportation Review, vol. 67, pp. 92-104, 2014.

[16] S. Panda, N. M. Modak, and L. E. Cárdenas-Barrón, "Coordinating a socially responsible closed-loop supply chain with product recycling," International Journal of Production Economics, vol. 188, pp. 11-21, 2017.

[17] J. Bian, K. W. Li, and X. Guo, "A strategic analysis of incorporating CSR into managerial incentive design," Transportation Research Part E: Logistics and Transportation Review, vol. 86, pp. 83-93, 2016.

[18] S. Panda, N. M. Modak, and D. Pradhan, "Corporate social responsibility, channel coordination and profit division in a two-echelon supply chain," International Journal of Management Science and Engineering Management, vol. 11, no. 1, pp. 1-12, 2014.

[19] S. Panda and N. M. Modak, "Exploring the effects of social responsibility on coordination and profit division in a supply 
chain," Journal of Cleaner Production, vol. 139, pp. 25-40, 2016.

[20] X. Chen, S. Benjaafar, and A. Elomri, "The carbon-constrained EOQ," Operations Research Letters, vol. 41, no. 2, pp. 172-179, 2013.

[21] C. M. Kunkel and D. M. Kammen, "Design and implementation of carbon cap and dividend policies," Energy Policy, vol. 39, no. 1, pp. 477-486, 2011.

[22] J. Bian, X. Guo, and K. W. Li, "Decentralization or integration: distribution channel selection under environmental taxation," Transportation Research Part E: Logistics and Transportation Review, vol. 113, pp. 170-193, 2018.

[23] L. Xia, W. Hao, J. Qin, F. Ji, and X. Yue, "Carbon emission reduction and promotion policies considering social preferences and consumers' low-carbon awareness in the cap-andtrade system," Journal of Cleaner Production, vol. 195, pp. 1105-1124, 2018.

[24] G. Hua, T. C. E. Cheng, and S. Wang, "Managing carbon footprints in inventory management," International Journal of Production Economics, vol. 132, no. 2, pp. 178-185, 2011.

[25] S. Du, F. Ma, Z. Fu, L. Zhu, and J. Zhang, "Game-theoretic analysis for an emission-dependent supply chain in a "capand-trade" system," Annals of Operations Research, vol. 228, no. 1, pp. 135-149, 2015.

[26] X. Xu, X. Xu, and P. He, "Joint production and pricing decisions for multiple products with cap-and-trade and carbon tax regulations," Journal of Cleaner Production, vol. 112, pp. 4093-4106, 2016.

[27] J. Xu, Y. Chen, and Q. Bai, "A two-echelon sustainable supply chain coordination under cap-and-trade regulation," Journal of Cleaner Production, vol. 135, pp. 42-56, 2016.

[28] P. Letmathe and N. Balakrishnan, "Environmental considerations on the optimal product mix," European Journal of Operational Research, vol. 167, no. 2, pp. 398-412, 2005.

[29] J. Song and M. Leng, "Analysis of the single-period problem under carbon emissions policies," International Series in Operations Research \& Management Science, vol. 176, no. 2, pp. 297-313, 2012.

[30] S. Du, L. Zhu, L. Liang, and F. Ma, "Emission-dependent supply chain and environment-policy-making in the "capand-trade" system," Energy Policy, vol. 57, pp. 61-67, 2013.

[31] Y. Zhou, W. Fang, M. Li, and W. Liu, "Exploring the impacts of a low-carbon policy instrument: a case of carbon tax on transportation in China," Resources, Conservation and Recycling, vol. 139, pp. 307-314, 2018.

[32] G. J. L. Micheli and F. Mantella, "Modelling an environmentally-extended inventory routing problem with demand uncertainty and a heterogeneous fleet under carbon control policies," International Journal of Production Economics, vol. 204, pp. 316-327, 2018.

[33] C. R. Carter and M. M. Jennings, "Social responsibility and supply chain relationships," Transportation Research Part E: Logistics and Transportation Review, vol. 38, no. 1, pp. 37-52, 2002.

[34] Z. Miao, S. Cai, and D. Xu, "Exploring the antecedents of logistics social responsibility: a focus on Chinese firms," International Journal of Production Economics, vol. 140, no. 1, pp. 18-27, 2012.

[35] C. R. Carter, R. Kale, and C. M. Grimm, "Environmental purchasing and firm performance: an empirical investigation," Transportation Research Part E: Logistics and Transportation Review, vol. 36, no. 3, pp. 219-228, 2000.

[36] D. H.-M. Wang, P.-H. Chen, T. H.-K. Yu, and C.-Y. Hsiao, "The effects of corporate social responsibility on brand equity and firm performance," Journal of business research, vol. 68, no. 11, pp. 2232-2236, 2015.

[37] R. Albuquerque, Y. Koskinen, and C. Zhang, "Corporate social responsibility and firm risk: theory and empirical evidence," Management Science, vol. 65, 2018.

[38] C.-F. Hsueh and M.-S. Chang, "Equilibrium analysis and corporate social responsibility for supply chain integration," European Journal of Operational Research, vol. 190, no. 1, pp. 116-129, 2008.

[39] D. Ni, K. W. Li, and X. Tang, "Social responsibility allocation in two-echelon supply chains: insights from wholesale price contracts," European Journal of Operational Research, vol. 207, no. 3, pp. 1269-1279, 2010.

[40] D. A. Phan, T. L. H. Vo, A. N. Lai, and T. L. A. Nguyen, "Coordinating contracts for VMI systems under manufacturer-CSR and retailer-marketing efforts," International Journal of Production Economics, vol. 211, pp. 98-118, 2019.

[41] Y. Shi, J. Nie, T. Qu, L.-K. Chu, and D. Sculli, "Choosing reverse channels under collection responsibility sharing in a closed-loop supply chain with re-manufacturing," Journal of Intelligent Manufacturing, vol. 26, no. 2, pp. 387-402, 2015.

[42] R. Pal and B. Saha, "Pollution tax, partial privatization and environment," Resource and Energy Economics, vol. 40, pp. 19-35, 2015.

[43] T. H. Cui, J. S. Raju, and Z. J. Zhang, "Fairness and channel coordination," Management Science, vol. 53, no. 8, pp. 1303-1314, 2007.

[44] S. Du, T. Nie, C. Chu, and Y. Yu, "Newsvendor model for a dyadic supply chain with Nash bargaining fairness concerns," International Journal of Production Research, vol. 52, no. 17, pp. 5070-5085, 2014.

[45] T. Nie and S. Du, "Dual-fairness supply chain with quantity discount contracts," European Journal of Operational Research, vol. 258, no. 2, pp. 491-500, 2017.

[46] S. Du, L. Wei, Y. Zhu, and T. Nie, "Peer-regarding fairness in supply chain," International Journal of Production Research, vol. 56, no. 10, pp. 3384-3396, 2018.

[47] Y. Wang, Z. Yu, and L. Shen, "Study on the decision-making and coordination of an e-commerce supply chain with manufacturer fairness concerns," International Journal of Production Research, vol. 57, no. 9, pp. 2788-2808, 2019.

[48] S. Panda, N. M. Modak, M. Basu, and S. K. Goyal, "Channel coordination and profit distribution in a social responsible three-layer supply chain," International Journal of Production Economics, vol. 168, pp. 224-233, 2015.

[49] B.-G. Son, C.-H. Lee, B.-C. Ha, and H. Nam, "Investigating the fair treatment of suppliers and its trust fostering role and performance benefits," International Journal of Production Economics, vol. 216, pp. 54-66, 2019.

[50] A. Y. Ha and S. Tong, "Contracting and information sharing under supply chain competition," Management Science, vol. 54, no. 4, pp. 701-715, 2008.

[51] K. G. Mäler, "National accounts and environmental resources," Environmental and Resource Economics, vol. 1, no. 1, pp. 1-15, 1991.

[52] S. J. T. Richard, "The damage costs of climate change toward more comprehensive calculations," Environmental \& Resource Economics, vol. 5, no. 4, pp. 353-374, 1995.

[53] P. Auger, P. Burke, T. M. Devinney, and J. J. Louviere, "What will consumers pay for social product features?" Journal of Business Ethics, vol. 42, no. 3, pp. 281-304, 2003.

[54] C. G. Ernst and Young, "Online availability of public services: how does Europe progress? Web-based survey on electronic 
public services," 2003, http://www.capgemini.dk/nyheder/ 2003/files/overall_report_2003.pdf.

[55] M. Kitzmueller and J. Shimshack, "Economic perspectives on corporate social responsibility," Journal of Economic Literature, vol. 50, no. 1, pp. 51-84, 2012. 